\title{
A new record of a giant neoepiblemid rodent from Peruvian Amazonia and an overview of lower tooth dental homologies among chinchilloids
}

Myriam Boivin, Pierre-Olivier Antoine, Aldo Benites-Palomino, Laurent Marivaux, and Rodolfo Salas-Gismondi

Acta Palaeontologica Polonica 64 (3), 2019: 627-642 doi:https://doi.org/10.4202/app.00609.2019

We report here a new record of the giant caviomorph Phoberomys corresponding to a fragmentary mandible from the Monte Salvado area, Peruvian Amazonia (Madre de Dios Department). We describe this specimen and compare it with the material previously attributed to Phoberomys. The mandibular fragment is referred to as Phoberomys sp. Found as float on a bank of the Río Las Piedras, it has been hypothetically assigned a late Miocene age, due to the local/regional stratigraphic and lithologic context. This specimen constitutes the second record of Phoberomys in Peru. For the first time, the pattern of p4s and lower molars in Phoberomys was analyzed and compared to a large taxonomic sample (including Paleogene-Recent chinchilloids and other caviomorphs) in order to progress the understanding of the homology of dental structures in this genus. For p4s and lower molars, the position of the protoconid in Phoberomys and other chinchilloids (Drytomomys sp., Potamarchus, Eumegamys, Gyriabrus, Isostylomys, and Tetrastylus) is ambiguous, and as a result we propose two alternative homology hypotheses for these taxa: protoconid within the first and second laminae or within the third lamina on juvenile specimens. The knowledge of a comprehensive ontogenetic sequence in extinct and extant chinchilloids, associated with more complete palaeontological records, would likely allow for a clarification of these homology ambiguities.

Key words: Mammalia, Rodentia, Phoberomys, mandible, Palaeogene, South America, Peru, Monte Salvado.

Myriam Boivin [myriam.boivin@univ-nantes.fr], Laboratoire de Planétologie et Géodynamique (LPG), UMR 6112, CNRS, Université de Nantes, Bât. 4, 2 Chemin de la Houssinière, F-44300 Nantes Cedex 3, France. Pierre-Olivier Antoine [pierre-olivier.antoine@umontpellier.fr ] and Laurent Marivaux [laurent.marivaux@umontpellier.fr], Laboratoire de Paléontologie, Institut des Sciences de l'Evolution de Montpellier (ISEM), UMR 5554 CNRS, IRD, EPHE, Université de Montpellier, Place Eugène Bataillon, F-34095 Montpellier Cedex 5, France. Aldo Benites-Palomino [aldomar1955@gmail.com ] and Rodolfo Salas-Gismondi [rsalasgismondi@gmail.com], Depar tamento de Paleontología de 
Vertebrados, Museo de Historia Natural, Universidad Nacional Mayor San Marcos (UNMSM, DPV-MUSM), Av. Arenales 1256, Lima 11, Peru.

This is an open-access article distributed under the terms of the Creative Commons

Attribution License (for details please see creativecommons.org), which permits unrestricted use, distribution, and reproduction in any medium, provided the original author and source are credited.

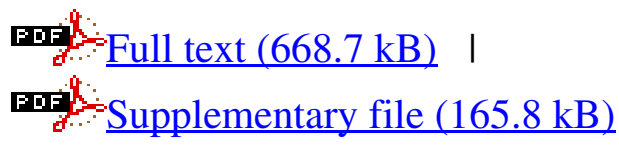

